\title{
Wood burial is currently the only fast and effective method of carbon neutrality
}

\author{
Kai Xu* \\ Fisheries College, Jimei University, Xiamen, 361021, China \\ * Correspondence: kaixu@jmu.edu.cn
}

\begin{abstract}
In this study, we analyzed the feasibility of various carbon neutrality methods based on the first principles of carbon sequestration, namely energy use efficiency and elemental stoichiometry. We believe that wood burial is the only currently feasible carbon neutrality method because this method has no theoretical uncertainties, can be implemented immediately on a large scale, has a long sequestration time, low cost, low technical requirements, and relatively little impact on agriculture.
\end{abstract}

Keywords: $\mathrm{CO}_{2}$, carbon neutrality, elemental stoichiometry, energy use efficiency, first principle, sink enhancement.

Carbon dioxide $\left(\mathrm{CO}_{2}\right)$ is one of the most important greenhouse gases and the main target for carbon neutrality. The major increment of atmospheric $\mathrm{CO}_{2}$ comes from the use of fossil fuels, so there are two pathways to reach net-zero emissions, the so-called carbon neutrality: emission reduction and sink enhancement. Currently, the annual carbon increment to the atmosphere is about $5 \times 10^{15} \mathrm{~g} \mathrm{C}{ }^{1,2}$. Therefore, a viable carbon neutrality program must be large in scale and capable of long-term implementation, and this program is essentially in long-term competition with the industrial capacity of human civilization. If the effect of a program is two orders of magnitude lower than emissions, it is of little practical significance; if it is three orders of magnitude lower, it is almost meaningless; if the effect of a program can reach $10 \%$ of emissions, it is highly feasible. Carbon neutrality involves several disciplines, but the research field of individuals is getting narrower and narrower, and the information explosion leads to the inability to judge the advantages and disadvantages of various carbon neutrality methods. Here, we analyzed the feasibility of several major carbon neutrality methods based on the first 
principles of carbon sequestration, namely energy use efficiency and elemental stoichiometry (FIG. 1).

\section{Economic pressure to emission reduction}

New energy sources such as solar energy, wind energy and nuclear energy still have many drawbacks and limitations, which lead to fossil fuels being the world's main energy source at present and in the coming decades. That's why China and the United States have set a clear plan to achieve carbon neutrality, not right now, but by 2060 and 2050, respectively. Emission reduction means reduce the use of fossil fuels; therefore, it will certainly affect the existing economic structure. Differences in national circumstances and differences in the implementation of reduction actions will put enormous pressure on the countries that reduce emissions first, leading to conflicting policies, wasted time, and increased costs. In many countries, the conflict between emission reduction and livelihood electricity consumption has attracted widespread attention. Therefore, there is an urgent need for viable sink enhancement programs to save time for the development of new energy technologies.

\section{Analysis and comparison of sink enhancement methods}

Sink enhancement is the conversion of gaseous $\mathrm{CO}_{2}$ into other types of inorganic or organic carbon and long-term storage. This long-term means that the stored carbon will not return to the atmosphere for at least a century, which is arguably the minimum standard for internationally recognized sink enhancement programs. For example, wood burial is a biological method of sink enhancement, referring to carbon sequestration through the production and long-term storage of dry wood. One popular inorganic method for sink enhancement is to liquefy $\mathrm{CO}_{2}$ and inject it into the ground. However, after more than 40 years of development, this inorganic method remains highly controversial and more than $80 \%$ of commercial projects have failed ${ }^{3}$. Of particular note: liquid $\mathrm{CO}_{2}$ at $-20^{\circ} \mathrm{C}$ and $5 \mathrm{Mpa}$ has a density of $1059 \mathrm{~kg} / \mathrm{m}^{3}$ which is very close to the density of liquid water. A simple calculation shows that the carbon content per cubic meter of liquid $\mathrm{CO}_{2}$ is 0.29 tons, which is very close to that of dry wood. But the former is obviously much more expensive to produce and store. If the product of an inorganic method has a lower carbon content per unit volume than dry wood and a higher cost than wood 
production, then it is not as good as wood burial. Of course, sequestration of liquid $\mathrm{CO}_{2}$ has unique advantages over biological methods of sink enhancement, for example, it does not consume nitrogen, phosphorus and potassium nutrients.

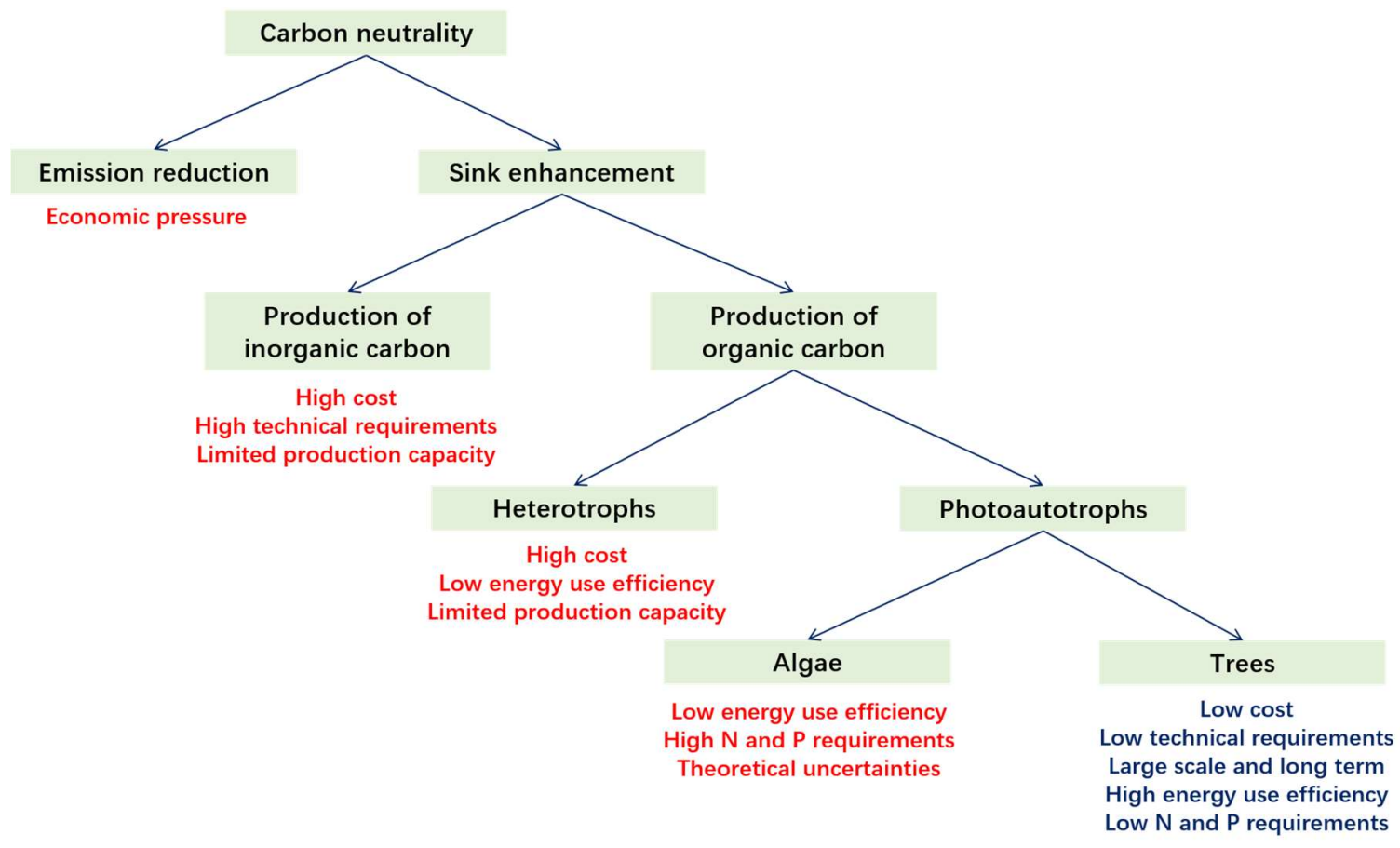

Fig. 1 Feasibility analysis of major carbon neutrality methods.

$\mathrm{CO}_{2}$ is a weakly acidic gas, thus alkalizing seawater with the addition of alkaline minerals would help it absorb more $\mathrm{CO}_{2}$, but this approach would require worldwide agreement and concerted action to make it work. Large-scale changes to the marine environment would have a huge impact on marine ecology and would most likely attract a lot of opposition.

The organic method for sink enhancement is to produce and store organic matter for a long-time using $\mathrm{CO}_{2}$ as a feedstock. The industrial synthesis of organic matter is obviously not yet available for large-scale sink enhancement, and the production of organic matter through cultivation of organisms is the only way to go at present. The energy transfer efficiency between trophic levels is quite low due to the large amount of energy that would be lost, suggesting that photoautotrophs have a much higher sink enhancement potential than other organisms.

Natural organic matter consists mainly of six elements: carbon, hydrogen, oxygen, nitrogen, 
phosphorus and sulfur, which account for more than $95 \%$ of living organisms ${ }^{1,4}$. Natural organic matter contains mainly four major classes of macromolecules, among which proteins are rich in nitrogen, nucleic acids and lipids are rich in nitrogen and phosphorus; while carbohydrates are very low in nitrogen and phosphorus. Therefore, the production of the first three organic matters for carbon neutrality will consume a large amount of nitrogen and phosphorus fertilizers, which will impact agricultural production causing food shortages and will cause a new round of intense competition for nitrogen and phosphorus resources. Among major photoautotrophs (Table 1), the carbon: nitrogen: phosphorus (C:N:P) molar ratio of trees is as high as 1360:8.5:1, which is much higher than seagrasses (550:30:1), marine macroalgae (550:30:1) and microalgae (106:16:1) ${ }^{1,5,6}$. If the product of an organic method has a higher nitrogen and phosphorus contents than wood, then it is no better than wood burial for sink enhancement in terms of nutrient requirement. If the production of certain organic matter needs to be involved with heterotrophs, then the energy use efficiency will be much lower than wood production.

Organisms mainly compete for food rich in nitrogen and phosphorus nutrients, which result in proteins, nucleic acids, and lipids being eaten or decomposed very quickly in natural environment. Wood is a solid and its main component is carbohydrates, these physical and chemical properties make it very easy to sequestrate carbon in the form of wood for more than 1000 years ${ }^{7}$. Even simple and low-cost techniques can significantly increase the time to carbon lockup. Due to the low C:N:P ratio of macroalgae and microalgae, they will be quickly utilized and decomposed, and most of the organic carbon fixed by photosynthesis will be turned back to $\mathrm{CO}_{2}$.

Almost all the organic carbon on the Earth surface is derived from photoautotrophs. Both marine microalgae and terrestrial plants contribute about half of the global net primary production (NPP), but the former accounts for only about $0.2 \%$ of the biomass of the latter ${ }^{8}$. It seems that marine microalgae have a great potential for sink enhancement. About $80 \%$ of the total marine NPP come from marine microalgae in open oceans, but at least $80 \%$ of the marine NPP is decomposed directly into $\mathrm{CO}_{2}$ in surface seawater, with less than $20 \%$ remaining sinking to the deep ocean, and about $98 \%$ of the sinking organic carbon is decomposed into $\mathrm{CO}_{2}{ }^{1}$. Thus, for marine microalgae in South China Sea, only about 
$2.5 \%$ of NPP is long-termly sequestered in the deep ocean with the involvement of bacteria and other microorganisms ${ }^{9}$. These data suggest that the efficiency (as a percentage of NPP) of carbon sequestration via microalgae cultivation is extremely low. Similar, but better, about $13 \%$ of NPP of marine macroalgae can be long-termly sequestered ${ }^{10}$. The plant carbon pool contains mainly terrestrial trees, and about $70 \%$ of plant biomass is wood ${ }^{1,4,7,11}$. Thus, the carbon sequestration efficiency of wood burial can be as high as $70 \%$, which is much higher than that of algae cultivation (Table 1).

Table 1 Carbon sequestration efficiency and nutrient requirement for biological sink enhancement methods.

\begin{tabular}{|c|c|c|c|c|c|c|}
\hline \multirow[b]{2}{*}{ Photoautotrophs } & \multicolumn{2}{|c|}{$\mathrm{C}: \mathrm{N}: \mathrm{P}$ ratio } & \multirow{2}{*}{$\begin{array}{c}\text { Carbon sequestration } \\
\text { efficiency }(\%)\end{array}$} & \multicolumn{3}{|c|}{ Nutrient requirement $(\%)$} \\
\hline & Body & $\begin{array}{l}\text { Sequestrated } \\
\text { organic matter }\end{array}$ & & $\mathrm{N}$ & $P$ & $\mathrm{~K}$ \\
\hline Trees & $1360: 8.5: 1$ & $1360: 8.5: 1$ & $70 \%$ & $24.3 \%$ & $27.9 \%$ & $149.7 \%$ \\
\hline $\begin{array}{c}\text { Macroalgae, Seagrasses } \\
\text { Microalgae }\end{array}$ & $\begin{array}{l}550: 30: 1 \\
106: 16: 1\end{array}$ & 200:14:1 & $\begin{array}{l}13 \% \\
2.5 \%\end{array}$ & $272.2 \%$ & $189.9 \%$ & 0 \\
\hline
\end{tabular}

Footnotes: Nutrient requirement are expressed as a percentage of industrial fertilizer production. To simplify the calculation of carbon sequestration efficiency, it is assumed that nitrogen and phosphorus exported to the deep sea can be completely reused for carbon sequestration.

Marine microalgae mainly distributed in the surface seawater of open oceans where the concentrations of available nitrogen, phosphorus, iron and silicon are normally very low ${ }^{3,12}$. The organic matter buried in marine sediments is the major form of long-term carbon sequestration in the ocean, with a C:N:P ratio of 200:14:1 ${ }^{1}$. Theoretically, microalgae biomass can be increased by fertilization in the oceans, which in turn could potentially increase the size of the sediment carbon pool derived from microalgae. However, this idea has several disadvantages: (1) The most important prerequisite is that organic matter originating from microalgae and sequestrated in the deep ocean and seafloor sediments can be increased. However, we cannot confirm this because the marine environment is changing and will probably change even more in the future. Large-scale water movements due to ocean circulation, storms, etc. can bring large amounts of organic carbon sequestered in the deep ocean and seafloor 
sediments to surface waters, which are then exposed to ultraviolet radiation and eventually converted to $\mathrm{CO}_{2}$ for release into the atmosphere ${ }^{13}$. Thus, the worst consequence is that if it is confirmed that ocean circulation is accelerating ${ }^{14}$, the size of marine organic carbon pool will keep decreasing; (2) The ocean is too deep and too wide, the diffusion effect causes fertilization to increase the nutrient concentration of surface seawater only for a short time, which inevitably results in a huge waste; (3) The number of microalgae per unit volume is very low, which leads to the fertilization concentration cannot be too high, otherwise the fertilizer cannot be fully utilized; (4) Microalgae are much higher in nitrogen and phosphorus contents than wood ${ }^{5}$ and have a large demand for fertilizer, brings large (relative to humans, but very small to the ocean) amounts of valuable nitrogen and phosphorus to the deep ocean. In particular, phosphorus resources are in very short supply ${ }^{1,4}$. It is worth noting that the cycle of marine nitrogen and phosphorus is not under human control; (5) It takes years to test and confirm the effect of fertilization on sink enhancement; (6) Fertilization in the open oceans requires a unified global opinion and may cause disputes in ecology and environmental protection; (7) Carbon sequestration by microalgae cultivation is very inefficient in terms of energy use because it requires the participation of other organisms. As a result, large-scale ocean fertilization projects are not only theoretically uncertain, but also inefficient, difficult to implement, and carry high environmental risks. One idea to combine inorganic and organic methods is to put alkaline inorganic minerals into the ocean to promote the absorption of $\mathrm{CO}_{2}$ by the ocean on the one hand, and to burial organic matter on the seabed to reduce decomposition on the other. This idea faces the same problems described above.

Zeng ${ }^{7}$ summarized four advantages of wood burial: (1) The plant carbon pool is comparable to the atmospheric carbon pool, thus wood can be preserved on a large scale; (2) Wood burial has the advantages of long-term sequestration, low technical requirements, low cost and easy management; (3) Burying old or dead trees and planting young trees can improve the efficiency of carbon sequestration because $\mathrm{CO}_{2}$ emission from decomposition will decrease and terrestrial NPP will increase; (4) By scientific management of global forests and wood production, forest fires can be reduced, which then reduces carbon emissions. Here, we given four additional advantages of wood burial compared with other biological method for sink enhancement from the perspective of elemental stoichiometry ${ }^{1,11,15,16 \text { : }}$ 
(1) The dry wood has a high carbon content, about $45 \%$ by weight; (2) Compared with cultivation of other photoautotrophs, the production of wood consumes less nitrogen and phosphorus nutrients and has less impact on agricultural production (Table 1); (3) About 70\% of plant biomass is wood ${ }^{11}$, which indicates the carbon sequestration efficiency can be as high as 70\%; (4) The contribution of wood burial to carbon neutrality can be easily calculated. These advantages make wood burial the only feasible method for carbon neutrality at present. Such carbon sequestration strategy need to manage global forests to achieving carbon neutrality due to the huge amount of $\mathrm{CO}_{2}$ emission, and therefore it would have an impact on forest ecosystems ${ }^{7}$.

In total, human activity emits $350 \times 10^{15} \mathrm{~g}$ of carbon into the atmosphere, about two-thirds of which comes from the burning of fossil fuels (origin from ancient plants) and one-third from tropical deforestation [4]. Wood burial can return carbon to its original form. Organic carbon is the basis of human civilization as well as the Earth's ecosystem, and wood has a wide range of uses and is likely to be a scarce resource in the future. Thus, developing the use of wood can encourage wood burial and thus enhance carbon sequestration.

\section{Wood burial program}

Zeng ${ }^{7}$ discussed many technical details of wood burial, and here we would like to discuss the feasibility in terms of nutrient requirements. The average density of dry wood is about 0.65 tons per cubic meter, with a carbon content of about $45 \%$ by weight ${ }^{15,16}$. Global annual net carbon emissions in 2019 are about $5 \times 10^{15} \mathrm{~g} \mathrm{C}^{2}$, equivalent to 17 billion cubic meters of dry wood. In addition to nitrogen and phosphorus, trees also have a high demand for potassium (K), with a C:N:K:P molar ratio of about 1360:8.5:4:1 $1^{1,15}$. USGS data show that global annual industrial productions of nitrogen, phosphorus and potassium fertilizers are about $150 \times 10^{12} \mathrm{~g} \mathrm{~N}, 34 \times 10^{12} \mathrm{~g} \mathrm{P}$ and $32 \times 10^{12} \mathrm{~g} \mathrm{~K}$, respectively [2] Assuming that all of the nitrogen and phosphorus absorbed by trees is used for wood production, then at least $24.3 \%, 27.9 \%$, and $149.7 \%$ of the industrial nitrogen, phosphorus, and potassium fertilizer produced globally each year, respectively, would need to be used to tree planting to achieve carbon neutrality. Knowledge about the content and distribution of elements in different tree species is limited 
and more research is needed to provide theoretical guidance for reducing the nutrient requirements of wood burial.

Based on $\mathrm{C}: \mathrm{N}: \mathrm{P}$ molar ratio, the nitrogen and phosphorus requirements for wood burial are significantly lower than for other biological methods (Table 1). Even so, a conflict between carbon neutrality and agriculture is already inevitable, and the world will face a severe shortage of nitrogen, phosphorus and potassium resources. Nutrients such as nitrogen, phosphorus and potassium are mainly enriched in the soft (active growth) parts, such as, leaves and shoots, thus these parts need to be recycled for wood production. Potassium can be extracted and obtained from seawater by biological (e.g., farming macroalgae, seagrasses, mangroves, etc.) or chemical methods. We can also use the nutrientrich non-agricultural land with net carbon emissions for tree planting. The soil organic carbon pool is about twice as large as the atmospheric carbon pool, and soil contain much more nitrogen and phosphorus contents than wood ${ }^{1,4,17}$, so its potential for use in wood production is very high.

\section{Summary}

The key to achieving carbon neutrality is to be able to implement it at a low cost and on a large scale. In this study, we analyzed the feasibility of various carbon neutrality methods from the perspective of energy use efficiency and elemental stoichiometry, and found that wood burial may be the only fast and effective method of carbon neutrality at present. Wood burial can be implemented immediately and on a large scale, with long sequestration time, low cost and technical requirements, and no theoretical uncertainties and relatively little impact on agriculture. Besides, it is clear that the implementation of carbon neutrality methods requires a globally integrated management of resources.

\section{Acknowledgements}

This work was supported by the National Key Research and Development Program of China (2018YFD0900702).

\section{Competing interests}


The author reports no potential conflicts of interest.

\section{References}

1 Schlesinger, W. H. \& Bernhardt, E. S. Biogeochemistry: an analysis of global change. (Elsevier, 2020).

2 Friedlingstein, P. et al. Global carbon budget 2019. Earth System Science Data 11, 1783-1838, doi:10.5194/essd-11-1783-2019 (2019).

3 Abdulla, A., Hanna, R., Schell, K. R., Babacan, O. \& Victor, D. G. Explaining successful and failed investments in U.S. carbon capture and storage using empirical and expert assessments. Environmental Research Letters 16, 014036, doi:10.1088/1748-9326/abd19e (2020).

4 Li, C. Biogeochemistry : scientific basis and modeling approach. (Tsinghua University Press, 2016).

5 Quigg, A. et al. The evolutionary inheritance of elemental stoichiometry in marine phytoplankton. Nature 425, 291-294 (2003).

6 Atkinson, M. J. \& Smith, S. V. C:N:P ratios of benthic marine plants1. Limnology and Oceanography 28, 568-574, doi:10.4319/lo.1983.28.3.0568 (1983).

7 Zeng, N. Carbon sequestration via wood burial. Carbon Balance Manag 3, 1, doi:10.1186/1750-0680-3-1 (2008).

8 Field, C. B., Behrenfeld, M. J., Randerson, J. T. \& Falkowski, P. Primary production of the biosphere: integrating terrestrial and oceanic components. Science 281, 237-240 (1998).

9 Ma, W., Xiu, P., Yu, Y., Zheng, Y. \& Chai, F. Production of dissolved organic carbon in the South China Sea: A modeling study. Science China Earth Sciences, doi:10.1007/s11430-021-9817-2 (2021).

10 Hughes, A. D. et al. Does seaweed offer a solution for bioenergy with biological carbon capture and storage? Greenhouse Gases: Science and Technology 2, 402-407, doi:10.1002/ghg.1319 (2012).

11 Bar-On, Y. M., Phillips, R. \& Milo, R. The biomass distribution on Earth. Proc Natl Acad Sci U S A, doi:10.1073/pnas.1711842115 (2018).

12 Moore, C. M. et al. Processes and patterns of oceanic nutrient limitation. Nature Geoscience 6, 701-710, doi:10.1038/ngeo1765 (2013).

13 Legendre, L., Rivkin, R. B., Weinbauer, M. G., Guidi, L. \& Uitz, J. The microbial carbon pump concept: Potential biogeochemical significance in the globally changing ocean. Progress in Oceanography 134, 432-450, doi:10.1016/j.pocean.2015.01.008 (2015).

$14 \mathrm{Hu}, \mathrm{S}$. et al. Deep-reaching acceleration of global mean ocean circulation over the past two decades. Science advances 6, eaax7727, doi:10.1126/sciadv.aax7727 (2020).

15 Taiz, L. \& Zeiger, E. Plant physiology. 5th. (Sinauer Associates, 2010).

16 ToolBox, E. Density of Various Wood Species, <https://www.engineeringtoolbox.com/wooddensity-d_40.html [Accessed 27 Dec. 2021]> (2004).

17 Tipping, E., Somerville, C. J. \& Luster, J. The C:N:P:S stoichiometry of soil organic matter. Biogeochemistry 130, 117-131, doi:10.1007/s10533-016-0247-z (2016). 